\title{
DRAGONFLIES AS PREDATORY ENEMIES OF THE STABLE-FLY (STOMOXYS CALCITRANS)
}

\author{
By Charles T. Brues \\ Biological Laboratories, Harvard University
}

Two accounts have recently been published ${ }^{1}$ of observations showing that dragonflies commonly capture stable-flies in considerable numbers. These relate to Florida Gulf beaches, and recall similar observations made by us some years ago at a second, far distant locality in northern Canada.

This was on the shores of Cedar Lake in northern Manitoba (Lat. $53^{\circ} \mathrm{N}$ ) where we spent a part of the summer of 1936 with the primary purpose of collecting fossil insects contained in Cretaceous amber which occurs in quanity on one of the beaches bordering the western end of the lake.

The ever-present swarms of mosquitoes make the short summer season almost unbearable for man and beast alike and we had been warned that these would be supplemented from time to time by other small biting flies. From the description of this pest given us by the Indian who selected our camp site it appeared probable that it must be the stable-fly.

This surmise proved to be correct. A fortnight later when we returned to camp on the evening of July 5th from the beach where our collecting was done we were assailed by numbers of stable-flies which bit with the persistence that they exhibit whenever abundant, especially in the absence of other mammalian hosts. They were present in considerable numbers while the evening meal was being prepared and eaten, and we resigned ourselves to accepting them as camp mates for some time to come.

On the next evening they appeared in still greater abundance and the outlook grew more unpleasant. Shortly afterward, during the long twilight which persists for several hours at that

\footnotetext{
${ }^{1}$ Dove, W. E. and S. W. Simmons. Control of the Stablefly or "dog fly" Breeding in Shore Deposits of Bay Grass. Journ. Econ. Entom., vol. 28, pp. 582-589 (1942).

Wright, M. Dragonflies Predaceous on the Stablefly (Stomoxys calcitrans). Florida Entom., vol. 28, pp. 11-13; 31-32.
} 
season, great numbers of dragonflies appeared in the air above the camp and within a few minutes the stable-flies had disappeared. Moreover they did not reappear during the several remaining weeks of our stay at Cedar Lake, although each evening numerous dragonflies were to be seen feeding in the air above us.

The dragonflies were not identified, but appeared to be a large species of Æschnidæ which appeared most abundantly at dusk, darting about in such numbers that we could occasionally hear the impact of their bodies as they collided in the air. Midges and mayflies are extremely abundant since there are endless opportunities for them to develop in the lake as well as in the spruce swamps and the other marshy areas characteristic of the region. Dragonflies are likewise a conspicuous element of the insect fauna just as they are along our southern Atlantic and Gulf coasts. The stable-fly population at Cedar Lake, however, cannot compare to the almost incredible numbers which regularly infest our southeastern beaches.

The stable-fly is undoubtedly an old world species, possibly native to India, but was reported to be abundant in Philadelphia as early as 1776 , and appears at present to enjoy a distribution about as wide as that of any insect.

\section{Polydrusus Sericeus Schall.}

This European species is listed in the Leng list as occurring in Indiana. In 1941 from May 25 to June 22 I took a number of them on poplar and again in Framingham in 1943 they were abundant on Corylus americana, poplar and maple near the same locality. This year (1945) they were again abundant especially on Corylus about June 10th. The European species of these green weevils are very numerous, or at least the names are, and the present species resembles many of them. Superficially they resemble large Polydrusus impressifrons Gyll., Phyllobius pyri L. and also the green form of Scythropus elegans Coup. Phyllobius glaucus Scop. is recorded from "Can." but probably this is a misidentification of $P$. pyri since the specimens from $\mathrm{Mr}$. William Procter taken at Bar Harbor, Me., were first identified as $P$. glaucus.

- C. A. Frost 

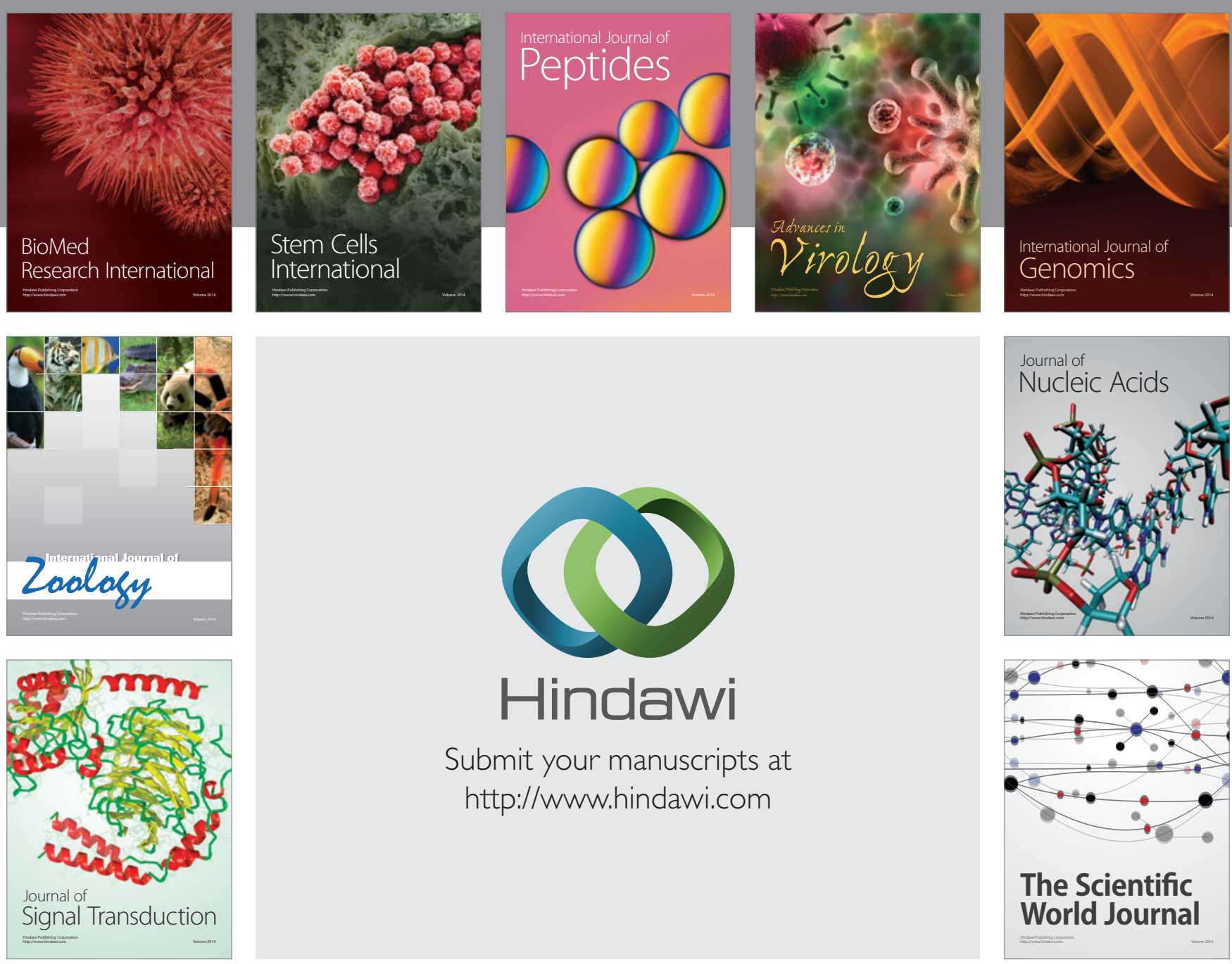

Submit your manuscripts at

http://www.hindawi.com
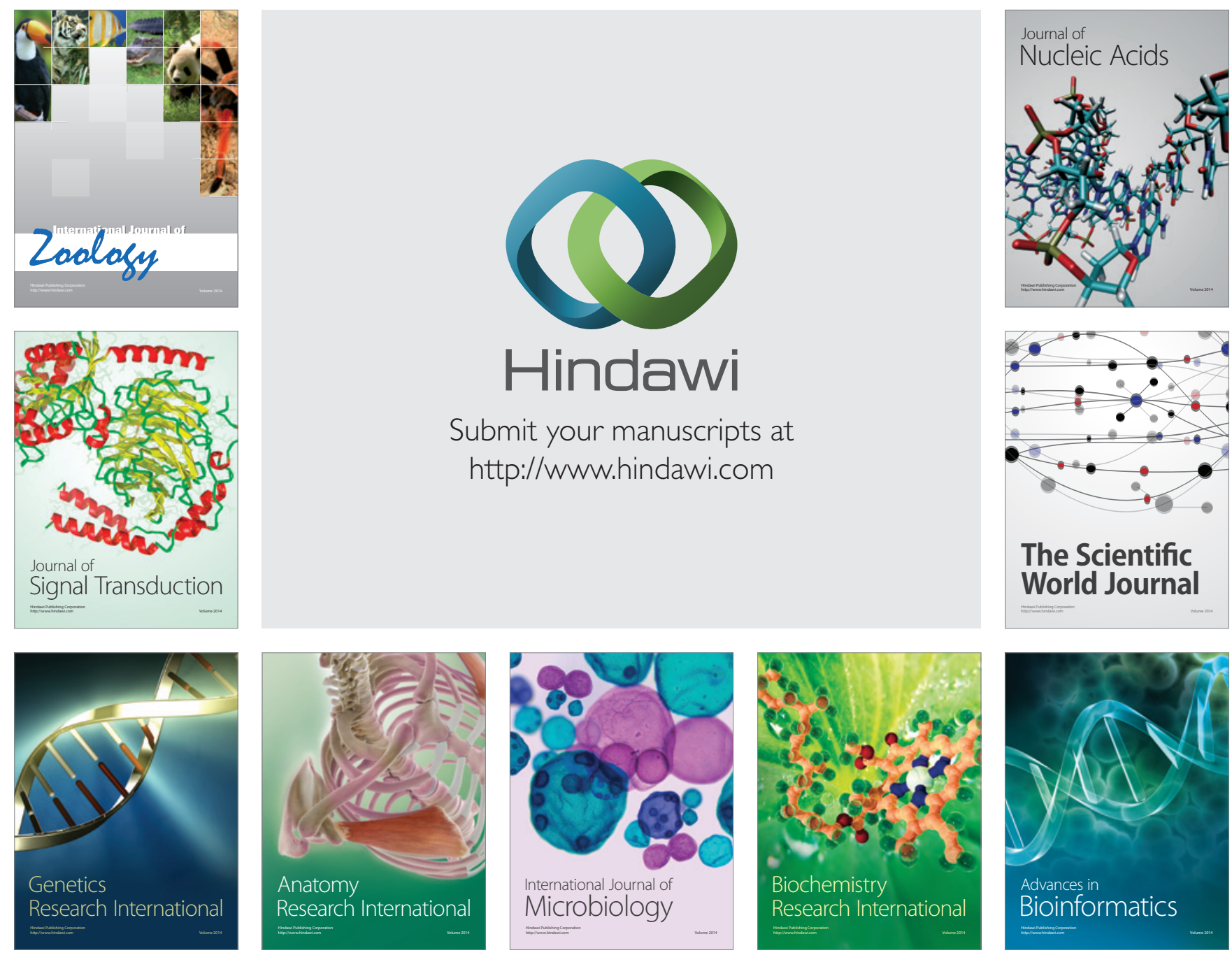

The Scientific World Journal
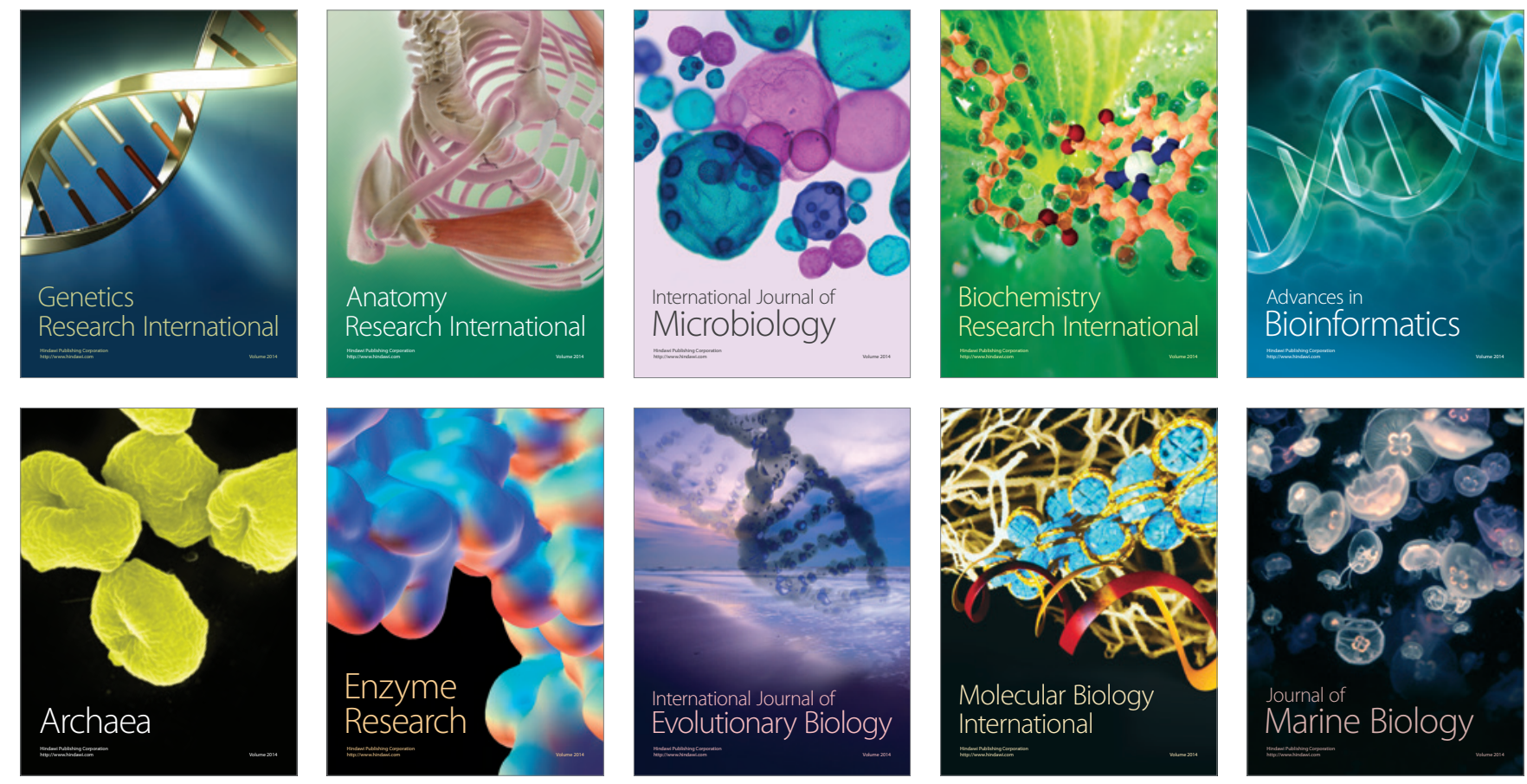